Belyavin, G., Miles, E. M. \& Miles, A. A. (1951). J. gen. Microbiol. 5, 178-196.

\title{
The Serology of Fifty Strains of Proteus vulgaris
}

\author{
By G. BELYAVIN, ELLEN M. MILES AND A. A. MILES
}

National Institute for Medical Research, London, N.W. 7

SUMMARY : Of fifty strains of Proteus vulgaris from human infections, seven of the 'vulgaris' and forty-three of the 'mirabilis' fermentative type, forty-four were brought into Belyavin's phase $A$, which represents the modal $S$ form of recently-isolated strains, and analysed serologically by their $H$ and $O$ antigens. Three of the six remaining strains were irreversibly $\mathbf{R}$, and three were too unstable antigenically for the routine analysis.

The antigens determining the somatic $O$ types were resistant to heating at $95^{\circ}$, to ethanol and to dilute $\mathrm{HCl}$, treatments that destroyed the $\mathbf{H}$ antigens. Serologically similar $\mathrm{O}$ antigens were extracted from the bacilli by hot formamide and by ethanol precipitation of tryptic digests.

As in other recent surveys of Proteus serology, the classification of strains by major $\mathrm{O}$ antigens was more clear-cut than by $\mathrm{H}$ antigens, though some minor $\mathrm{O}$ antigens were distributed differently from the major. 'The forty-four phase-A strains fell into eighteen O-antigenic types, three of these being the classical OX2, OX 19 and OXK types, strains of which were included in the survey. The $H$ antigens of each strain were often apparently multiple, but grouping by major $\mathbf{H}$ antigens was broader than by $\mathrm{O}$ antigens; moreover, $\mathrm{H}$ antigens were often common to strains with dissimilar $\mathrm{O}$ antigens.

Apart from the antigenic changes accompanying variation from phase $A$ to phases $\mathbf{B}$ or $\mathbf{C}$, there were suggestions of other phasic variations in both $\mathbf{H}$ and $\mathbf{O}$ antigens, which, if substantiated, may necessitate a reconsideration of serological classifications of the group. The three unstable strains in the collection could not be definitely assigned to any $\mathrm{O}$-antigenic type.

The serological study of Proteus vulgaris and closely allied microbes covers a period of fifty years. The earlier work was directed, among other things, mainly to finding a species antigen by which $P$. vulgaris could be identified (Wolf, 1899; Klieneberger, 1908; Cantu, 1911; van Loghem \& van Loghem-Pouw, 1912; Horowitz, 1916; Bengston, 1919; Wenner \& Rettger, 1919; Taylor, 1928). As a result of these investigations, it was generally conceded that $P$. vulgaris was antigenically heterogeneous. One type of heterogeneity in Proteus spp., the distinction of flagellar and somatic antigens, was discovered by Weil \& Felix who also discovered differences in the $\mathrm{O}$ antigens of the classical strains, $\mathrm{X} 19$, X2 (Weil \& Felix, 1917; Weil, 1920, 1923; Felix, 1923). With the description of the XK strain (Fletcher \& Lesslar, 1926) a third O-antigen complex was recognized.

Work on the flagellar and somatic antigens of the Proteus group during the past twenty years has defined the heterogeneity of the species antigens more fully (Moltke, 1927; Yacob, 1932; Varela, Zozaya \& Imaz, 1944; Winkle, 1943, 1944; Rustigian \& Stuart, 1945; Perch, 1948) with regard to both $\mathrm{H}$ and $\mathrm{O}$ antigens. In particular, Winkle (1944) and Perch (1948) have made a detailed receptor analysis of their strains and have numbered or lettered the determinant groups identified, thus allotting an antigenic 'formula' to each strain and group. 
In the course of her investigations, Perch tested Winkle's type strains with her own sera.

Our serological investigation started in 1936, with the collection of 21 strains from human infections (see Miles, 1951) and of authentic stock strains for comparison. The serological analysis was interrupted by the 1939-45 war, during which most of the strains were maintained in stock nutrient agar stabs. A number of Proteus strains from infected burns were collected in 1943. On the resumption of serological work in 1946, many of the somatic serological characters previously found in the pre-war strains had disappeared or were difficult to elicit; and those even of the more recent burn strains were variable on retest. For this reason, the status of each stock strain was re-investigated (Belyavin, 1951), with the discovery of a modal phase A, equivalent to the fully Smooth form of other Gram-negative enterobacteria, and two other phases, B and C, of which B corresponds to a partially Rough form, with loss of the type $\mathrm{O}$-antigen, saline-stability and virulence for mice. Since the variations $\mathbf{A} \rightarrow \mathbf{B}$ and $\mathbf{A} \rightarrow \mathbf{C}$ were reversible, it proved possible to coax most of the degraded stock strains into phase $\mathbf{A}$, and we report below an analysis of the $\mathbf{O}$ and $\mathbf{H}$ antigens of $\boldsymbol{P}$. vulgaris in Belyavin's phase $\mathbf{A}$.

Symbols. We have used the sign PR, followed by a number, to designate our strains, except for those which were already named (X2, X 19, etc.). Suspensions treated to destroy flagellar antigens, and the corresponding antisera, are labelled OPR 1, OPR3, etc.; and suspensions of flagellated forms and antisera to them, HPR 1, HPR 3, etc. A collection of strains having the same phase A $\mathbf{O}$-antigen constitute a 'type', and those with the same main $\mathbf{H}$ antigen, a 'group'; but we intend these terms to be only temporary descriptions pending an agreed designation for the Proteus antigens.

\section{Character and source of the strains}

The strains were isolated from human urinary, wound, pleural and burn infections (where they were either the sole or the predominant microbe as judged by examination of morbid material and direct plate cultures), with the exception of six strains from collections, and PR 37 and 39, from laboratory mice dying of an intercurrent spontaneous Proteus infection during toxicity tests with Brucella endotoxins.

All strains were typical $\boldsymbol{P}$. vulgaris, swarming on $2 \%$ nutrient agar, liquefying gelatin, producing $\mathrm{H}_{2} \mathrm{~S}$ from peptone water and splitting urea with the production of $\mathrm{NH}_{3}$. Of the fifty strains, seven (PR 5, X2, XL, X 19, PR 29, 37, 39) were ' $P$. vulgaris Hauser' (Bergey, 1948), in that they readily fermented maltose and sucrose, and readily produced indole. One (PR 36) readily though feebly fermented maltose and sucrose, and was indole-negative; and the remaining forty-two were ' $P$. mirabilis Hauser' (Bergey, 1948), being indolenegative, and failing to ferment maltose or sucrose within 5 days. Both the 'vulgaris' and 'mirabilis' varieties are called $\boldsymbol{P}$. vulgaris throughout this paper.

Pus strains. PR 5, 7, 9, 10, 13, 19, 21.

Urinary strains. PR 1, 3, 4, 11, 12, 15, 16, 17, 18, 20, 22, 23, 31, 32, 33, 35, 36.

Mouse strains. PR 37 and 39. 
Burn strains. PR 41-52, isolated in 1943 by Dr L. Colebrooke from infected burns in ten patients during a ward outbreak of Proteus infection; and PR 53-58, from five patients during a second outbreak in a burns ward.

Stock strains. Proteus X2; Proteus X19; Proteus XK; Proteus XL (all from Col. H. J. Bensted); PR 29, P. vulgaris originally from Prof. Rettger (Wenner \& Rettger, 1919); PR 30, N.C.T.C. 3156, selected because it was reported to react serologically with Brucella antisera. We also received from Dr F. Kauffmann seventy-one of the strains used by Dr Perch in her analysis, representing forty-nine of the somatic groups described in the simplified antigenic schema of Kauffmann \& Perch (Perch, 1948). Some of these strains were tested against sera representing seventeen of our somatic types, with a view to identifying receptors common to the two classifications.

Up to 1945, the strains were maintained in soft agar stabs, subcultured at 6-weekly or 2-monthly intervals; in 1946 and after, they were kept in the dry state by Stamp's (1947) method.

\section{METHODS}

\section{Preparation of phase $A$ strains}

Stability of suspensions. The strains were tested for thermal, saline and acriflavine stability. Thick suspensions in distilled water were killed by heating for $1 \mathrm{hr}$. at $56^{\circ}$, and diluted to $2 \times 10^{9}$ cells $/ \mathrm{ml}$. for the saline, and to $8 \times 10^{9} / \mathrm{ml}$. for the thermal tests (Pandit \& Wilson, 1932), the density being estimated in a simple visual comparator against a counted suspension of $2 \times 10^{9}$ Salmonella typhi $/ \mathrm{ml}$. The $8 \times 10^{9} / \mathrm{ml}$. suspensions were heated in a $95^{\circ}$ bath for $60 \mathrm{~min}$. and examined during the heating at $15 \mathrm{~min}$. intervals; and the $2 \times 10^{9} / \mathrm{ml}$. suspensions mixed with equal volumes of $5,4,3,2,1$ and $0 \%$ solution of $\mathrm{NaCl}$, and read after $18 \mathrm{hr}$. incubation at $50^{\circ}$.

The acriflavine test, described by Pampana (1933), was made on a number of single colonies on MacConkey agar cultures of each strain by suspending them in a drop of $0.85 \%$ saline on a slide, and mixing with an equal volume of $1 / 500$ acriflavine in $0.85 \%$ saline. Agglutination of the cells, readily visible with a $\times 3$ lens within 2 min., was recorded as positive. It is clear from Table 1 that acriflavine stability is not associated with saline and thermal stability. Heat-stable suspensions give rise as often as heat-labile suspensions to acriflavine unstable colonies and in comparable proportions; and in only one instance did the selection of an acriflavine-stable colony affect the heat stability of the strain. Comparison of the acriflavine and the saline tests is less valid because saline stability was at first tested with flagellated suspensions. Later work proved that flagellated suspensions were often saline-stable when the derived $O$ suspensions were unstable. In any series of colonies from a strain quite stable to both heat and saline, acriflavine-stable colonies may nevertheless be exceedingly rare. We finally abandoned the acriflavine test as a method of selecting smooth strains. The decision was also justified by the fact that many variants, which later proved to be antigenically degenerate and to have lost virulence, were as acriflavine-stable as the parent strain. 
Table 1. The relation of thermal, saline and acriflavine stability of flagellated strains of Proteus vulgaris

\begin{tabular}{|c|c|c|c|c|}
\hline \multirow[b]{2}{*}{ Strain } & \multirow[b]{2}{*}{ Source } & \multicolumn{2}{|c|}{ Agglutination by } & \multirow{2}{*}{$\begin{array}{l}\text { Acriflavine } \\
\text { test* }\end{array}$} \\
\hline & & Saline & Heat $\left(95^{\circ}\right)$ & \\
\hline \multirow[t]{3}{*}{ PR 1} & (a) From stock & + & 0 & $3 / 20$ \\
\hline & (b) Acriflavine-stable, from $(a)$ & 0 & 0 & $6 / 10$ \\
\hline & (c) After mouse-passage & $\mathbf{0}$ & 0 & $0 / 5$ \\
\hline \multirow[t]{3}{*}{ PR 3} & (a) From stock & 0 & 0 & $2 / 20$ \\
\hline & (b) Acriflavine-stable, from (b) & $\mathbf{0}$ & $\mathbf{0}$ & $3 / 9$ \\
\hline & (c) After mouse-passage & 0 & 0 & $0 / 5$ \\
\hline \multirow[t]{3}{*}{ PR 23} & (a) From stock & + & + & $2 / 20$ \\
\hline & (b) Acriflavine-stable, from $(a)$ & tr. & 0 & $2 / 6$ \\
\hline & (c) After mouse-passage & 0 & 0 & $0 / 5$ \\
\hline PR 4 & From stock & 0 & $\mathbf{0}$ & $0 / 7$ \\
\hline
\end{tabular}

Selection of colony types for preparation of suspensions. All the parent strains and variant forms discovered during the investigation could be assigned to one of the three phases described by Belyavin (1951). The colonial types found could be divided into a modal phase $\mathbf{A}$, which always gave rise to saline-stable $O$ suspensions, and at least two other phases of which one (B) had an antigenic constitution of different specificity when tested against a series of fifteen somatic antisera, and tended to be unstable in saline suspensions. Whereas the phase $\mathbf{A}$ antigens were type specific, the antigenic complex of the $\mathbf{B}$ variant had two new antigens, one of broader specificity, a cosmopolitan antigen, the other narrower-indeed, strain specific. These components were present on the surface in varying amounts as judged by agglutination and absorption tests, together with small amounts of the type-specific antigen; moreover, even predominantly type-specific strains contained small amounts of the $\mathbf{B}$ phaseantigenic complex. These antigenic components could be detected in suspensions by the use of appropriate antisera, and serological tests of suitability eventually replaced those for saline and thermal stability.

Flagellar $(H)$ suspensions. The dry stock cultures were seeded into CCY broth (Gladstone \& Fildes, 1940) incubated for 5-6 hr. at $37^{\circ}$ and plated on to MacConkey's agar. The next day, single colonies were seeded on to nutrient agar, the $20 \mathrm{hr}$. growth washed off with distilled water, centrifuged once, and resuspended in distilled water. The suspension was killed by heating at $56^{\circ}$ for $1 \mathrm{hr}$. and preserved by $0 \cdot 25-0 \cdot 4 \%$ formalin. Such suspensions were adequate for absorbing flagellar antibody, but in many instances were inferior to liquid cultures as agglutinating suspensions. Liquid cultures were prepared by inoculating single colonies into $40 \mathrm{ml}$. of $1 \%$ peptone water, incubating for $3-5 \mathrm{hr}$. at $37^{\circ}$ and then at $22-25^{\circ}$ for 3 days. The cultures were killed by heat and formalized without washing.

On the whole, slightly higher titres were obtained with the formalized peptone cultures, and the agglutination was more floccular. However, the flagellar agglutination of a strain was sometimes variable, and occasional subculture by swarming over a $2 \%$ agar surface, or through $0.5 \%$ nutrient agar in $U$ tubes 
was necessary to produce a strongly agglutinating flagella suspension. With some strains even this treatment failed.

Somatic $(O)$ suspensions. Since non-motile, non-swarming strains may be flagellated, though poorly (Colquhoun \& Kirkpatrick, 1932) we did not attempt to induce non-motile variant strains for making $\mathbf{O}$ suspensions, but relied on the destruction of $\mathbf{H}$ antigens by ethanol, and by acid (Duncan, 1935). One volume of $0.01 \mathrm{~N}-\mathrm{HCl}$ at $37^{\circ}$ was added to an equal volume of distilled water suspension in a water-bath. After $5 \mathrm{~min}$. a one-tenth volume of $0.1 \mathrm{~N}-\mathrm{NaOH}$ was added to stop the reaction. The suspension was centrifuged once, resuspended in distilled water and heated for $1 \mathrm{hr}$. at $56^{\circ}$; preservative was not added. The rate of destruction of flagella at a given temperature and acidity is a function of bacterial density (Duncan, 1935). We confirmed that this treatment completely destroyed all flagellar antigen in suspensions containing $100 \times 10^{9}$ cells or less $/ \mathrm{ml}$; all suspensions for acid treatment were diluted first to this concentration. The acid method is quick and simple, but suspensions of heat- and saline-agglutinable strains became much more so during acid treatment and were unsuitable for serological tests. Ethanol treatment, on the other hand, made these unstable forms more stable (Belyavin, 1951), and because we wished to analyse all forms serologically, it was adopted as a routine. Ethanolized type-specific suspensions induced good antibody formation in rabbits, and agglutinated more strongly than type-specific, acid-treated suspensions, although the latter gave slightly more consistent end-points in repeated titrations. We must emphasize that modal phase A (type-specific) strains yielded equally stable suspensions whether they were treated with acid or ethanol and gave precisely the same serological results.

The suspensions were prepared by washing off a nutrient agar culture in $96 \%$ methylated spirit and heating for $1 \frac{1}{2} \mathrm{hr}$. at $56^{\circ}$. The suspension was spun down, washed twice in distilled water, finally resuspended in distilled water and stored at $+5^{\circ}$. No preservative was added. We did not use as a routine $\mathrm{O}$ suspensions prepared by heating to $100^{\circ}$ for 30 or $60 \mathrm{~min}$., as recommended by Perch (1948). With phase A strains the results with ethanol, $\mathrm{HCl}$ and heating to $100^{\circ}$ were identical, but phase $\mathbf{B}$ and phase $\mathrm{C}$ strains, initially unstable, were often more so by this treatment, and it was convenient to use ethanol, which was suitable for all three phases. Moreover, the results of $\mathbf{H C l}$ treatment were useful in detecting phase B strains (Belyavin, 1951).

Preparation of antisera. Albino rabbits, $2-3.5 \mathrm{~kg}$. in weight, were immunized by the bi-weekly intravenous injection of bacterial suspension. The initial dose was $10^{8}$ organisms and the dose was doubled at each injection, six to seven doses being given. Usually 'first-course' bleedings were used; a second course of injections sometimes induced a broadening of specificity in the resulting antisera, and 'second-course' bleedings were seldom used.

\section{Serological methods}

Agglutination tests. Twofold dilutions of antisera were mixed with an equal volume $\left(0.3 \mathrm{ml}\right.$.) of suspensions containing $2 \times 10^{9} \mathrm{cells} / \mathrm{ml}$. and held at $50^{\circ}$. $\mathrm{H}$ agglutination was read at 4 and $18 \mathrm{hr}$. and $\mathrm{O}$ agglutination after $18 \mathrm{hr}$. The 
end-point of the titrations was the reciprocal of the serum dilution producing agglutination barely perceptible to the naked eye, but easily visible with a $\times 3$ hand-lens when viewed by oblique illumination against a dark background ('standard' agglutination). For intermediate values in the two-fold series, interpolation factors were calculated by the method of Dreyer \& Inman (1917). As in the Salmonellae, $\mathrm{H}$ and $\mathrm{O}$ agglutination respectively were floccular and granular.

Slide agglutinations were used in screening tests of $O$ suspensions against type sera. Two loopsful ( $2 \mathrm{~mm}$. loop) of neat serum were mixed with $c .0 .05 \mathrm{ml}$. of ethanolized $\mathrm{O}$ suspension containing about $50 \times 10^{9}$ cells $/ \mathrm{ml}$., i.e. a final serum dilution of $1 / 3-1 / 5$. The test was read in oblique transmitted light after rocking the slide for 1-2 min. The agglutinations were quite clear-cut and easy to read. Slide agglutination tests are liable to be falsely negative when compared with tube titrations, unless highly diluted sera are used. To establish the reliability of the slide test, ninety titrations were made in parallel (Table 2).

Table 2. The relation between slide and tube agglutination tests of $O$ suspensions of Proteus vulgaris

\begin{tabular}{|c|c|c|c|c|c|c|c|}
\hline \multirow[b]{3}{*}{ Serum no. } & \multicolumn{3}{|c|}{ Slide negative } & \multicolumn{3}{|c|}{ Slide positive } & \multirow[b]{3}{*}{ Totals } \\
\hline & \multirow{2}{*}{$\begin{array}{c}\text { Tube } \\
\text { negative }\end{array}$} & \multicolumn{2}{|c|}{ Tube positive } & \multirow{2}{*}{$\begin{array}{c}\text { Tube } \\
\text { negative }\end{array}$} & \multicolumn{2}{|c|}{ Tube positive } & \\
\hline & & $\mathrm{Up}$ to 20 & $\overbrace{>20}$ & & Up to 20 & $>20$ & \\
\hline 1 & 13 & 0 & 0 & 0 & 0 & 2 & 15 \\
\hline 2 & 15 & 0 & 0 & 0 & 0 & 0 & 15 \\
\hline 3 & 12 & 1 & 0 & 0 & 0 & 2 & 15 \\
\hline 4 & 14 & 1 & 0 & 0 & 0 & 0 & 15 \\
\hline 5 & 13 & 2 & 0 & 0 & 0 & 0 & 15 \\
\hline 6 & 11 & $\mathbf{0}$ & 0 & 0 & 2 & 2 & 15 \\
\hline Totals & 78 & 4 & 0 & 0 & 2 & 6 & 90 \\
\hline
\end{tabular}

In ninety tests, four were slide-negative but tube-positive. All four, however, gave tube titres, which, being less than $\frac{1}{100}$ th part of the homologous titre, were not significant in type identification. A similar series of thirty tests with four other sera, but containing a higher proportion of slide-positive suspensions gave similar results. It was not uncommon to find that slide-positive suspensions were agglutinated only to low titres in tubes. The slide test then is reasonably reliable for 'screening' ethanolized $\mathrm{O}$ suspensions.

Absorption tests. Two methods of absorption were used. In one, the serum at a fixed dilution (1/10 or 1/20) was absorbed by an equal volume of falling concentrations of antigen, and after centrifugation the supernatant from each tube tested directly against one or more suspensions. In the other, after absorption of the serum with a single concentration of antigen, the residual antibody was titrated in the usual manner. In both cases the absorption was carried out for $2 \mathrm{hr}$. at $37^{\circ}$. Both tests were used in parallel, one acting as a check on the other, when small numbers of strains and sera were involved. When more than three strains and three sera were tested the second method was used as being more economical of time and materials. Table 3 exemplifies 
both methods in determining the antigenic relationship of two strains falling within the same somatic type. When a serum was absorbed, particularly by a heterologous strain, the agglutinins were usually more completely removed by low concentrations of absorbing antigen than with high, as is evident in Table 3a. For absorption of sera in bulk, therefore, a low multiple of the minimal absorbing dose was always used. For a large number of suspensions, the absorbed sera were first tested by the slide method to eliminate non-reacting strains.

Table 3. 'Mirror' cross-absorption tests in which a given serum dilution is (a) absorbed by graded doses of antigen, and $(b)$ by a single dose of antigen $\left(5 \times 10^{9}\right.$ cells $/ \mathrm{ml}$. $)$ with subsequent titration of residual antibody

(a)

Initial conc. of absorbing suspension $\left(10^{\%} / \mathrm{ml}\right.$.)

\begin{tabular}{|c|c|c|c|c|c|c|c|c|}
\hline \multicolumn{3}{|c|}{ Serum $(1 / 10)$} & 80 & 40 & 20 & 10 & 5 & $\mathbf{0}$ \\
\hline Against & Absorbed $\mathrm{b}$ & ested against & \\
\hline \multirow[t]{2}{*}{ PR 7} & OPR 7 & $\begin{array}{l}\text { OPR 7 } \\
\text { OPR } 10\end{array}$ & $\begin{array}{l}\text { S } \\
0\end{array}$ & $\begin{array}{l}\text { S } \\
0\end{array}$ & $\begin{array}{l}\text { tr. } \\
0\end{array}$ & $\begin{array}{l}\text { tr. }+ \\
0\end{array}$ & $\begin{array}{l}\mathbf{T}- \\
\mathbf{0}\end{array}$ & $\begin{array}{l}\mathbf{T}- \\
\mathbf{T}-\end{array}$ \\
\hline & OPR 10 & $\begin{array}{l}\text { OPR 7 } \\
\text { OPR } 10\end{array}$ & $\begin{array}{l}\text { T- } \\
\text { tr. }\end{array}$ & $\begin{array}{l}S+ \\
\text { tr. }\end{array}$ & $\begin{array}{l}\text { T- } \\
\text { tr. }\end{array}$ & $\begin{array}{l}S+ \\
\text { tr. }+\end{array}$ & $\begin{array}{l}\text { T- } \\
\text { tr. }\end{array}$ & $\begin{array}{l}\text { nt } \\
\text { nt }\end{array}$ \\
\hline \multirow[t]{2}{*}{ PR 10} & OPR 7 & $\begin{array}{l}\text { OPR } 7 \\
\text { OPR } 10\end{array}$ & $\begin{array}{l}\text { tr. } \\
\text { T- }\end{array}$ & $\begin{array}{l}\text { tr. }+ \\
\mathbf{T}-\end{array}$ & $\begin{array}{l}\text { tr. }+ \\
\mathbf{T}-\end{array}$ & $\begin{array}{l}\text { tr. }+ \\
\text { T- }\end{array}$ & $\begin{array}{l}\text { tr. }+ \\
\text { T- }\end{array}$ & $\begin{array}{l}\mathbf{T}- \\
\mathbf{T}-\end{array}$ \\
\hline & OPR 10 & $\begin{array}{l}\text { OPR 7 } \\
\text { OPR } 10\end{array}$ & $\begin{array}{l}\mathbf{0} \\
\mathbf{S}\end{array}$ & $\stackrel{0}{S+}$ & $\begin{array}{l}\mathbf{0} \\
\mathrm{S}+\end{array}$ & $\begin{array}{l}\mathbf{0} \\
\mathbf{0}\end{array}$ & $\begin{array}{l}\mathbf{0} \\
\mathbf{0}\end{array}$ & $\begin{array}{l}\text { nt } \\
\text { nt }\end{array}$ \\
\hline
\end{tabular}

tr., tr. $+, \mathbf{S}, \mathbf{S}+, \mathbf{T}-, \mathbf{T}=$ degrees of trace, 'standard' and total agglutination; $\mathrm{nt}=$ no test; $0=$ no agglutination.

$\begin{array}{ccccc}\text { Serum (1/10) } & \begin{array}{c}\text { Tested against } \\ \text { suspension }\end{array} & \overbrace{\text { Nil }} & \text { OPR 7 } & \text { OPR 10 } \\ \text { OPR 7 } & \text { OPR 7 } & 1280 & 80 & 640 \\ \text { OPR 10 } & \text { OPR 10 } & \mathbf{3 2 0} & <\mathbf{2 0} & \mathbf{2 0} \\ & \text { OPR 7 } & 320 & 20 & <20 \\ & \text { OPR 10 } & 1280 & 640 & <20\end{array}$

\section{RESULTS}

The phase $A$ somatic antigens

Table 4 shows the cross-reactions of HCl-treated suspensions from strains with their corresponding sera. It is arranged to display the main agglutinating types. A few are singleton strains, that is, they react only with their own sera, and their sera do not agglutinate any other strain in the collection. A summary of all types with their component strains is given in Tables $5 a$ and $b$. Eighteen serological types emerge from forty-four strains, of which ten are singletons. Three strains, PR 5, 20 and 41, were irreversibly rough when tested in 1948. It was not possible to classify PR 19, 21, and 22 by agglutination reactions, because the strains were unstable, with a variable antigenic type. Both PR 19 and PR 21 at times exhibited affinities with the X2 type and PR 19 and PR 22 
with type 10. The lability of these strains is well exemplified by the behaviour of PR 19. The stock strain was at first Rough, but the apparently stable phase A selected from it reacted moderately with an X2 antiserum. Tested 4 days later, it had lost its $\mathrm{X} 2$ reactivity, and agglutinated to low titre with a type 10 serum; when tested a week later, it would react with none of the phase A sera. The other two varied analogously but both finally reached a state when they reacted to a very low titre with over half a dozen phase A sera, as though they were now characterized by a minor 'cosmopolitan' antigen. No serum was prepared against PR58, the fiftieth strain, but since it failed to agglutinate with any of the type $\mathrm{O}$-antisera, it is presumably a singleton.

Table 5a. The $O$ antigenic types of forty-four phase $A$ strains of Proteus vulgaris, including the four classical $O X$ strains

\begin{tabular}{|c|c|c|}
\hline Somatic type & PR strains & Total \\
\hline 1 & 1,12 & 2 \\
\hline 2 & $4,9,31$ & 3 \\
\hline 3 & $11,17,18^{*},(30), 35,45,49,56$ & 8 \\
\hline 4 & 7,10 & 2 \\
\hline 5 & $44,46,47,48,50,52,54,55,57$ & 9 \\
\hline 6 & 51 & 1 \\
\hline 7 & 53 & 1 \\
\hline 8 & 29 & 1 \\
\hline 9 & 43 & 1 \\
\hline 10 & 32 & 1 \\
\hline 11 & 36 & 1 \\
\hline 12 & 33 & 1 \\
\hline 13 & 37, 39 & 2 \\
\hline 14 & 16 & $\overline{1}$ \\
\hline 15 & 58 & 1 \\
\hline X 2 & $\mathbf{X} 2$ & 1 \\
\hline \multirow{4}{*}{$\begin{array}{l}\mathrm{X} 19 \\
\mathrm{XK} a \\
b\end{array}$} & $\mathbf{X 1 9}, \mathbf{X L}$ & 2 \\
\hline & $23,(42), \mathrm{XK}\}$ & 6 \\
\hline & $3,13,15\}$ & $\mathbf{b}$ \\
\hline & Total & 44 \\
\hline
\end{tabular}

Table 5b. $H$ antigenic groups of twenty phase $A$ strains of Proteus vulgaris, including the four classical $X$ strains

\begin{tabular}{clc}
$\begin{array}{c}\text { Flagellar } \\
\text { group }\end{array}$ & \multicolumn{1}{c}{ PR strains } & Total \\
A & 4,9 & 2 \\
B & $1,3,10,12,13,15,23$ & 7 \\
C & $7,11,17,19,22, \times 2, \times 19$, XK, XL & 9 \\
D & 16 & 1 \\
E & 21 & 1
\end{tabular}

In both tables, numbers in heavy type indicate strains against which sera were prepared.

Types containing more than one strain are discussed below, especially those that are heterogeneous with respect to their minor antigens.

Somatic types 1, 2 and 3 . These three types, containing two, three and eight 
strains respectively, are each antigenically homogeneous; each component strain will remove all the $\mathrm{O}$ antibody from the type sera. This, of course, does not preclude the possibility of strains belonging to these types, with heterogeneous minor antigens. Strain PR 18 is not classed as type 3 by agglutination or absorption tests; the strain is rough, although strain-specific receptors are present. However, it contains a trace of the type 3 antigen, because it induces type 3 antibody in the rabbit.

Type $X K$. This type certainly includes five strains: PR 3, 13, 15, 23 and XK and possibly PR 42. Strains PR3, 13 and 15 agglutinate to a lower titre than strains PR 23, and XK with OXK antiserum. Conversely, strains XK and PR 23 agglutinated to low titres with PR3 and 15 antisera. The cross-adsorption tests with ethanolized suspensions (Table 6 ) subdivide the type into two, $a$ and $b$, the classical XK strain falling in type XKa. All these strains are antigenically distinct from the other X strains, X 2, X 19 and XL.

\section{Table 6. Cross-absorption of tests of type OXK strains}

\begin{tabular}{|c|c|c|c|c|c|c|c|}
\hline \multirow[b]{2}{*}{ Serum } & \multirow{2}{*}{$\begin{array}{l}\text { Tested against } \\
\text { suspension }\end{array}$} & \multicolumn{6}{|c|}{ Titre after absorption by } \\
\hline & & Nil & OPR 3 & OPR 13 & OPR 15 & OPR 23 & OXK \\
\hline \multirow[t]{5}{*}{ OPR 3} & OPR 3 & 320 & 0 & 0 & 80 & 160 & 160 \\
\hline & OPR 13 & 160 & 0 & $\mathbf{0}$ & 40 & 80 & 80 \\
\hline & OPR 15 & 80 & 0 & $\mathbf{0}$ & $<20$ & $<20$ & $<20$ \\
\hline & OPR 23 & 40 & nt & nt & nt & nt & nt \\
\hline & OXK & 40 & nt & nt & nt & nt & nt \\
\hline \multirow[t]{5}{*}{ OPR 15} & OPR 3 & 320 & $\mathbf{0}$ & $\mathbf{0}$ & $\mathbf{0}$ & 80 & 80 \\
\hline & OPR 13 & 320 & 0 & $\mathbf{0}$ & $\mathbf{0}$ & $\mathbf{0}$ & 0 \\
\hline & OPR 15 & 1280 & 0 & 0 & 0 & 0 & 0 \\
\hline & OPR 23 & 100 & 0 & $\mathbf{0}$ & $\mathbf{0}$ & 0 & 0 \\
\hline & OXK & 80 & 0 & 0 & 0 & 0 & 0 \\
\hline \multirow[t]{5}{*}{ OXK } & OPR 3 & 640 & 160 & 120 & 40 & $\mathbf{0}$ & $\mathbf{0}$ \\
\hline & OPR 13 & 1280 & 240 & 160 & 80 & $\mathbf{0}$ & $\mathbf{0}$ \\
\hline & OPR 15 & 1280 & 240 & 240 & 160 & $\mathbf{0}$ & $\mathbf{0}$ \\
\hline & OPR 23 & 2560 & 480 & 480 & 480 & $\mathbf{0}$ & $\mathbf{0}$ \\
\hline & OXK & 2560 & 1280 & 1280 & 1280 & $\mathbf{0}$ & 0 \\
\hline
\end{tabular}

Difficulties in classification are raised by the behaviour of strains PR 30 and PR 42. PR30 reacts strongly with sera for subtypes $a$ and $b$, but PR 42 does not react with the subtype $a$ sera, and only agglutinates to $5 \%$ of full titre with subtype $b$. Nevertheless, its own serum agglutinates OXK to at least $50 \%$ of full titre; moreover, PR 30 carries an antigen reacting to full titre with the sera of the otherwise quite distinct type 3, and PR 42 has an antigen not related to any other in the collection. It is not clear, therefore, whether these strains should, in fact, be referred to the XK type. Two of Dr Perch's strains behaved similarly, i.e. as though possessing an XK antigen in addition to that characterizing a different somatic type. We have no evidence that such an antigenic constitution is quantitatively variable, with one or other type antigen bredominating at the surface in different phases. If phase variation of this 
kind were proved, the validity of the XK type antigen as a constant feature characterizing XK strains would need reconsideration.

Type 4. This consists of two strains, PR 7 and PR 10. They cross-agglutinated, but not to reciprocally equal titres. The two strains are not antigenically homogeneous (Table $\mathbf{3} a$ ).

Type 13. This consists of two antigenically homogeneous strains, PR 37 and 39.

Type $X 2$ and $X 19$. These types, although antigenically distinct, may be considered together, as they are represented in the collection by only three strains, viz. X2, X 19, and XL. Strain X2 is a singleton. On the other hand strains X19 and XL as originally described are closely related although not homogeneous (Table 7). Whereas XL removes agglutinins for both itself and

Table 7. Cross-absorption tests of Proteus $O X 19$ and $O X L$

\begin{tabular}{|c|c|c|c|c|c|c|c|c|}
\hline \multicolumn{3}{|c|}{ Serum $(1 / 20)$} & \multicolumn{6}{|c|}{ Initial conc. of absorbing suspension $\left(10^{9} / \mathrm{ml}\right.$.) } \\
\hline Against & Absorbed by & Tested against & 80 & 40 & 20 & 10 & $\mathbf{5}$ & $\mathbf{0}$ \\
\hline \multirow[t]{2}{*}{ OXL } & OX 19 & $\begin{array}{l}\text { OX } 19 \\
\text { OXI }\end{array}$ & $\begin{array}{l}0 \\
\mathrm{~S}+\end{array}$ & $\begin{array}{l}\mathbf{0} \\
\mathbf{T}-\end{array}$ & $\begin{array}{l}\mathbf{0} \\
\mathbf{T}-\end{array}$ & $\begin{array}{l}\mathbf{S}- \\
\mathbf{T}\end{array}$ & $\begin{array}{l}\mathbf{T} \\
\mathbf{T}\end{array}$ & $\begin{array}{l}\mathrm{T} \\
\mathrm{T}\end{array}$ \\
\hline & OXL & $\begin{array}{l}\text { OX } 19 \\
\text { OXL }\end{array}$ & $\begin{array}{l}0 \\
0\end{array}$ & $\begin{array}{l}\mathbf{0} \\
\mathbf{0}\end{array}$ & $\begin{array}{l}\mathbf{0} \\
\mathbf{0}\end{array}$ & $\begin{array}{l}\mathbf{0} \\
\mathbf{S}+\end{array}$ & $\begin{array}{l}\mathrm{S} \\
\mathrm{T}-\end{array}$ & $\begin{array}{l}\text { nt } \\
\text { nt }\end{array}$ \\
\hline \multirow[t]{2}{*}{ OX 19} & OX 19 & $\begin{array}{l}\text { OX } 19 \\
\text { OXL }\end{array}$ & $\begin{array}{l}0 \\
0\end{array}$ & $\begin{array}{l}0 \\
0\end{array}$ & $\begin{array}{l}0 \\
0\end{array}$ & $\begin{array}{l}\mathbf{T}- \\
\mathbf{T}-\end{array}$ & $\begin{array}{l}\mathbf{T} \\
\mathbf{T}\end{array}$ & $\begin{array}{l}\mathbf{T} \\
\mathbf{T}\end{array}$ \\
\hline & OXL & $\begin{array}{l}\text { OX } 19 \\
\text { OXL }\end{array}$ & $\begin{array}{l}\mathbf{S}+ \\
\mathbf{S}+\end{array}$ & $\begin{array}{l}\mathrm{S}+ \\
\mathrm{S}+\end{array}$ & $\begin{array}{l}\text { tr. }+ \\
\text { tr. }\end{array}$ & $\begin{array}{l}\text { T- } \\
\text { tr. }+\end{array}$ & $\begin{array}{l}\mathbf{T}- \\
\mathbf{T}\end{array}$ & $\begin{array}{l}\text { nt } \\
\text { nt }\end{array}$ \\
\hline
\end{tabular}

Symbols as in Table $\mathbf{3}$.

X19 from anti-XL serum, X19 even in high concentration, removes only its own antibody. Conversely, $\mathrm{XL}$ does not remove all antibody from the X19 antiserum, although it obviously removes more of its own agglutinin. The relationship of these two strains is of considerable interest. The results described suggest that they differ in their somatic antigens only by the presence of an additional receptor in strain XL, and in this we agree with Kauffmann \& Perch (1947). On the other hand, Winkle (1944) allots the additional antigen to strain X19 and identifies it also in strain X2. The ethanolized OXL suspension used gave a well-marked though partial agglutination to a titre of 640 with a strong phase B serum $(58 \alpha)$ which did not occur with OX19. The antigen that distinguishes XL from X19 may therefore be a phase B antigen. The two strains may be even more complex. A bacteriophage from the Pasteur Institute reported to act on the Proteus strain OXL, when tested against subcultures of $\mathbf{X}$ strains obtained from the National Collection of Type Cultures, indeed attacked the strain XL but not X19. In the case of the X strains we received from Col. Bensted, however, OX 19 was attacked and not OXL. This discrepancy is unexplained.

Types 6, 7, 8, 9, 10, 11, 12, 14 and 15. These types are all represented by single strains. It is possible that some of these, notably PR 16, are in a 'strainspecific' phase. Type 9 contains PR36. This strain has a 'rough' colonial 
morphology and tends to be unstable in high concentrations of saline. The creation of an $\mathrm{O}$ type to accommodate this strain must be regarded as tentative.

Somatic antigen-analysis by precipitin reaction. Two kinds of soluble extract were tested against $\mathrm{O}$-antisera, and gave identical results. The first was obtained by ethanol precipitation of tryptic digests of acetone-extracted cells (Miles, 1951) and the second, more simply by treating the centrifuged deposit from $2 \mathrm{ml}$. of a 5 or $20 \mathrm{hr}$. culture in CCY broth with hot formamide, by the method of Fuller (1938). The extract was layered on undiluted serum and precipitation at the interface occurred within $10 \mathrm{~min}$. at room temperature. Eighteen strains were tested against sixteen sera (Table 8). The reactions confirm the results with cross-agglutination tests (Table 4), but strains belonging to antigenically heterogeneous types are sharply separated into subtypes without crossprecipitation; e.g. the reactions between PR 3, 13, 15, 23 and XK, and of PR7 and 10. The effect might be due to selective extraction of different fractions, or to a concentration effect; the same sera were used for agglutination and precipitation, and, being induced by one or at most two courses of injections, perhaps contained insufficient antibody for a visible heterologous precipitin reaction. The formamide method which can be applied to $2 \mathrm{ml}$. of a $5 \mathrm{hr}$. culture would clearly be useful for rapid $O$ typing of Proteus strains.

Table 8. The cross-precipitation reactions of sixteen antisera and formamide extracts of eighteen phase $A$ strains of Proteus vulgaris

O-Antisera to (PR)

\begin{tabular}{|c|c|c|c|c|c|c|c|c|c|c|c|c|c|c|c|c|}
\hline from (PR) & 4 & 9 & 3 & 23 & XK & 30 & 11 & 17 & 7 & 10 & X19 & XL & X2 & 1 & 21 & 32 \\
\hline 4 & + & + & - & - & - & - & 一 & - & - & - & - & - & - & - & - & - \\
\hline $\mathbf{9}$ & & 7 & 一 & - & 一 & & 一 & & 一 & - & - & - & - & - & - & - \\
\hline 3 & - & - & + & - & - & - & - & - & - & - & - & - & - & - & - & 一 \\
\hline 12 & - & - & + & - & - & - & - & - & - & - & - & - & - & - & 一 & - \\
\hline 15 & - & - & + & - & - & - & - & - & - & - & - & - & - & - & - & 一 \\
\hline $2:$ & - & - & - & + & + & - & - & - & - & - & - & - & - & - & - & - \\
\hline XK & 一 & - & - & + & + & - & - & - & - & - & - & - & - & 一 & - & - \\
\hline 30 & - & - & - & - & - & \pm & - & - & - & - & - & - & - & - & - & - \\
\hline 11 & - & - & - & - & - & + & + & + & - & - & - & - & - & - & - & - \\
\hline 17 & - & - & - & - & - & + & + & + & - & - & - & - & - & - & - & - \\
\hline 7 & - & 一 & 一 & - & 一 & - & - & - & + & - & - & - & 一 & 一 & - & - \\
\hline 10 & - & - & - & - & 一 & - & 一 & - & - & + & 一 & - & - & - & 一 & - \\
\hline$\times 19$ & - & - & - & - & 一 & 一 & - & - & - & - & + & \pm & - & - & - & - \\
\hline XL & - & - & - & - & - & - & 一 & - & - & - & \pm & + & - & 一 & - & - \\
\hline $\mathrm{X2}$ & - & - & - & - & - & - & - & - & - & - & - & 一 & $t$ & - & - & - \\
\hline 1 & - & - & - & - & 一 & - & - & 一 & - & - & - & - & - & + & - & - \\
\hline 21 & - & - & - & - & - & - & - & 一 & - & 一 & 一 & - & - & - & + & - \\
\hline 32 & 一 & - & - & - & - & - & - & - & - & - & - & - & - & - & - & + \\
\hline
\end{tabular}

The flagellar antigens

Table 9 shows the flagellar cross-agglutination titres for nineteen of the strains in the collection; the analysis was not carried beyond this point. Eighteen fall into five groups, containing respectively one, one, two, seven and nine 
strains and comprising strains belonging to nine $O$ types. The word 'group' is not used here in the strict sense of a serological class, but merely implies a collection of strains, and these we designate A, B, C, D and E (Table $5 b$ ).

They are not as clearly defined as the $O$ types by the cross-agglutination reactions, and cross-absorption tests reveal that all are antigenically heterogeneous.

Table 9. The $H$-agglutination reactions of fifteen sera and nineteen phase $A$ strains of Proteus vulgaris

\begin{tabular}{|c|c|c|c|c|c|c|c|c|c|c|c|c|c|c|c|}
\hline \multirow{2}{*}{$\begin{array}{l}\text { H-sus- } \\
\text { pension } \\
\text { of } \\
\text { (HPR) }\end{array}$} & \multicolumn{15}{|c|}{$\mathrm{H}$-antisera to (HPR) } \\
\hline & 9 & 4 & 1 & 3 & 13 & 23 & 15 & $X K$ & 19 & 17 & 11 & X19 & $\mathrm{X} 2$ & $X L$ & 16 \\
\hline 9 & 2560 & 7600 & 60 & 0 & 0 & 0 & 0 & 0 & 0 & 0 & 80 & 0 & 80 & 0 & 0 \\
\hline 4 & 3800 & 10240 & 60 & 0 & 0 & 0 & 0 & 0 & 0 & 0 & 80 & 0 & 160 & 0 & 0 \\
\hline 12 & 0 & 0 & 1280 & 5120 & 0 & 120 & 0 & 0 & 0 & 0 & 0 & 0 & 0 & 0 & 0 \\
\hline 1 & 0 & 0 & 1280 & 5120 & 3800 & $>10240$ & 30 & 2560 & 0 & 0 & 0 & 0 & 0 & 0 & \\
\hline 3 & 0 & 0 & 2000 & 20000 & 250 & 160 & 3800 & 640 & 0 & 0 & 0 & 0 & 0 & 0 & 0 \\
\hline 13 & 320 & 0 & 480 & 1280 & 5120 & 2560 & 480 & 480 & 0 & 0 & 0 & 0 & 80 & 0 & \\
\hline 23 & 0 & 0 & 1000 & 120 & 1280 & $>20480$ & 640 & 15360 & 0 & 0 & 0 & 0 & 60 & 0 & 0 \\
\hline 15 & 320 & 160 & 1280 & 7600 & 320 & 80 & 5120 & 120 & 0 & 0 & 0 & 0 & 80 & 0 & \\
\hline 10 & 0 & 0 & 750 & 5000 & 3000 & 160 & $<40$ & 10000 & 5000 & 5120 & 160 & $\mathrm{nt}$ & 0 & 0 & 0 \\
\hline 7 & 0 & 0 & 0 & 0 & 160 & 0 & 80 & 15360 & 160 & 160 & 3800 & 3800 & nt & 750 & \\
\hline $\mathrm{XK}$ & 0 & 0 & 0 & 160 & 0 & 160 & 40 & 15360 & 240 & 2560 & 5120 & 2560 & 1280 & 640 & 0 \\
\hline 19 & 0 & 0 & 0 & 0 & 0 & 0 & 0 & 640 & 3800 & 3800 & 0 & 0 & 0 & 0 & \\
\hline 17 & 0 & 0 & 0 & 0 & 0 & 0 & 0 & 160 & nt & 5120 & 80 & $<40$ & $<40$ & $<40$ & \\
\hline$\times 19$ & 0 & 0 & 0 & 0 & 0 & 0 & 0 & 20480 & 160 & 640 & 1280 & 5120 & 1280 & 1280 & \\
\hline $\mathrm{X} 2$ & 0 & 0 & 0 & 160 & 0 & 0 & 0 & 10240 & 120 & 5120 & 3800 & 2600 & 1280 & 1000 & \\
\hline XL & 0 & 0 & 0 & 0 & 0 & 0 & 0 & 15360 & 1000 & 5120 & 3800 & 1280 & 1280 & 1280 & \\
\hline 11 & 0 & 0 & 0 & 60 & 0 & 0 & 0 & 15360 & 0 & 1280 & 5120 & 2560 & 2000 & 1280 & \\
\hline 22 & 0 & 0 & 0 & 0 & 0 & 0 & 0 & 15360 & 0 & 160 & 1280 & 3750 & 0 & 160 & \\
\hline 16 & 0 & 0 & 0 & 0 & 0 & 0 & 0 & 0 & 0 & 0 & 0 & 0 & 0 & 0 & 7620 \\
\hline
\end{tabular}

$A, D$ and $E$ groups. PR 4 and 9 comprise the A group. Their flagellar antigens are not entirely homogeneous, and they differ in at least one receptor. D group is represented by PR16, and E by PR21. Both have an antigenic flagellar constitution distinct from that of the other strains examined.

$B$ group. Strains PR 12, 1, 3, 13, 23, 15 and 10 constitute B group. Crossabsorption of three anti-sera HPR 3, HPR 23 and HXK by four of the strains (Table 10) show at least three distinct antigens and from the cross-agglutination tests of PR 12 and XK, two others may be inferred. One receptor carried by HXK is common to the whole group.

C group. This is formed by the strains PR7, PR 19, PR17, X19, X2, XL, PR 11 and PR 22. XK can also be considered as falling mainly in this group, but its exact relationship is discussed below. The cross-absorptions with three of the main sera (Table 11) reveal the distribution of four antigens. The strains 19 and 17, as they agglutinate only with their own sera and with that of XK, can be considered as forming a minor subdivision and might with justification be taken out of the major group of strains. They are retained, however, on the basis of their antigenic relationship with strain XK.

The flagellar antigens of PR 7, 11, 22 and strains X 19, X2, XL and XK have something in common. It is noteworthy that $\mathrm{XK}$ has wide antigenic relationships, and it is of particular interest that although the antiserum against $\mathbf{X K}$ agglutinates both group B (PR 1, 3, 12, 13, 15, 23, 10) and group C (PR 7, 19, 11, 22 and strains $\mathrm{X} 19, \mathrm{X} 2, \mathrm{XL})$ to a high titre, it was itself agglutinated only by the sera of group C (Table 9 ). 
Table 10. Cross-absorption tests of strains in flagellar antigen, group $B$

\begin{tabular}{|c|c|c|c|c|c|c|}
\hline \multirow[b]{3}{*}{ Serum } & \multirow{3}{*}{$\begin{array}{l}\text { Tested against } \\
\text { suspension } \\
\text { (HPR) }\end{array}$} & \multicolumn{5}{|c|}{ Titre after absorption by } \\
\hline & & \multirow[b]{2}{*}{ Nil } & \multicolumn{4}{|c|}{ (HPR) } \\
\hline & & & 1 & $\mathbf{3}$ & 23 & XK \\
\hline \multirow[t]{5}{*}{ HPR 3} & 1 & 5120 & $<80$ & $<80$ & 80 & 320 \\
\hline & $\mathbf{3}$ & 20000 & 5120 & 1920 & 5120 & 3800 \\
\hline & 13 & 1280 & $<80$ & $<80$ & $<80$ & $<80$ \\
\hline & 15 & 7600 & 5120 & 1280 & 5120 & 5120 \\
\hline & 23 & 120 & $<80$ & $<80$ & $<80$ & $<80$ \\
\hline \multirow[t]{5}{*}{ HPR 23} & 1 & $>10240$ & 80 & 5120 & 80 & 3800 \\
\hline & 3 & 160 & $<80$ & $<80$ & $<80$ & $<80$ \\
\hline & 13 & 2560 & $<80$ & 2560 & $<80$ & 2560 \\
\hline & 15 & 80 & nt & nt & nt & nt \\
\hline & 23 & $>20480$ & 80 & 1920 & $<80$ & 2560 \\
\hline \multirow[t]{5}{*}{ HXK } & 1 & 2560 & $<80$ & $<80$ & $<80$ & $<80$ \\
\hline & $\mathbf{3}$ & 640 & $<80$ & $<80$ & $<80$ & $<80$ \\
\hline & 13 & 480 & $<80$ & $<80$ & $<80$ & $<80$ \\
\hline & 15 & 120 & $<80$ & $<80$ & $<80$ & $<80$ \\
\hline & 23 & 15360 & $<80$ & $<80$ & $<80$ & $<80$ \\
\hline
\end{tabular}

Table 11. Cross-absorption tests of strains in flagellar antigen, group C

Titre after absorption by

\begin{tabular}{|c|c|c|c|c|c|c|}
\hline \multirow[b]{2}{*}{ Serum } & \multirow{2}{*}{$\begin{array}{l}\text { Tested against } \\
\text { H suspension }\end{array}$} & \multirow[b]{2}{*}{ Nil } & \multicolumn{4}{|c|}{$(\mathrm{H})$} \\
\hline & & & XL & $\mathbf{X} 2$ & X 19 & $\mathbf{X K}$ \\
\hline \multirow[t]{7}{*}{ HXK } & XK & 15360 & 10240 & 10240 & 10240 & 80 \\
\hline & PR 19 & 640 & $<80$ & $<80$ & $<80$ & $<80$ \\
\hline & PR 17 & 160 & $<80$ & $<80$ & $<80$ & $<80$ \\
\hline & PR 11 & 15360 & 160 & 80 & 160 & 5120 \\
\hline & XL & 15360 & 2000 & 1000 & 160 & 10240 \\
\hline & $\mathbf{X} 2$ & 10240 & 2000 & 160 & 160 & 10240 \\
\hline & X19 & 20480 & 2000 & 160 & 640 & 15360 \\
\hline \multirow[t]{7}{*}{ HX 19} & XK & 2560 & $<80$ & $<80$ & $<80$ & $<80$ \\
\hline & PR 19 & $<40$ & nt & $\mathrm{nt}$ & nt & nt \\
\hline & PR 17 & $<40$ & nt & $\mathrm{nt}$ & nt & nt \\
\hline & PR 11 & 2560 & $<80$ & $<80$ & $<80$ & $<80$ \\
\hline & XL & 1280 & $<80$ & $<80$ & $<80$ & 640 \\
\hline & $\mathbf{X} 2$ & 2600 & $<80$ & $<80$ & $<80$ & 1280 \\
\hline & X19 & 5120 & $<80$ & $<80$ & $<80$ & 1000 \\
\hline \multirow[t]{7}{*}{ HPR 11} & XK & 5120 & $<80$ & $<80$ & $<80$ & $<80$ \\
\hline & PR 19 & $<40$ & nt & nt & nt & nt \\
\hline & PR 17 & 80 & nt & nt & nt & nt \\
\hline & PR 11 & 5120 & $<80$ & $<80$ & $<80$ & $<80$ \\
\hline & XL & 3800 & $<80$ & $<80$ & $<80$ & $<80$ \\
\hline & $\mathrm{X} 2$ & 3800 & $<80$ & $<80$ & $<80$ & 160 \\
\hline & X 19 & 1280 & $<80$ & $<80$ & $<80$ & 160 \\
\hline
\end{tabular}

The anomaly may have its basis in a diphasic variation. We attempted to discover such a variation by absorbing two portions of the XK antiserum with HX 19 and HXK respectively, and diluting the absorbed sera so that they were monospecific for HXK and HX19 respectively. The monospecific titres were about 1/30. Single colonies on MacConkey agar plated with the N.C.T.C. HXK 
and with Col. Bensted's strain of HXK were tested against both sera by the slide method. All colonies from the first strain were agglutinated equally well by both sera, whereas those from the Bensted strain went feebly or not at all with the monospecific 'HXK' serum, and in very different degrees with the monospecific 'HX 19' serum. The matter was not pursued, but the results, though providing no evidence for diphasic variation, suggest that the content, or the development of the flagellar antigenic components in the same strain, may be variable. Further work on these lines is necessary.

\section{Comparison of the antigenic complexes with those in Dr Perch's strains}

Forty-four of our strains were allotted to eighteen somatic types, of which three are the classical X types, X2, X19 and XK. We examined thirty-eight of Dr Perch's seventy-one strains, representing the thirty $O$ types fully described by Dr Perch in her extensive classification of 388 strains. We did not investigate the remaining nineteen types recorded in the simplified scheme of Kaufmann \& Perch (Perch, 1948) since the details of the minor antigen are not recorded. Excluding the necessary identities of the $\mathbf{X}$ strains common to both series, the correspondences were:

\begin{tabular}{ccc} 
Perch & \multicolumn{2}{c}{ Present paper } \\
${ }^{\prime} O$ 'group 30 & $=$ & $' O '$ type 2 \\
group 23 & $=$ & type 4 \\
group 4 & $=$ & type 10 \\
group 10 & $=$ & type 3
\end{tabular}

In addition, the strain F 10 (Perch $\mathrm{O}$ group 29) agglutinated with our $\mathrm{O}$ type 2 antiserum to approximately $10 \%$ of full titre, and U509 (Perch O group 28) to nearly $50 \%$ of full titre against our OPR 42 serum. Since U509 did not react with type XK sera it is provisionally assumed to share a minor antigen with strain PR 42.

It cannot be asserted that the antigenic constitutions of the identified types are identical in every case, but they are clearly closely related. The lack of correspondence between the type composition of the two samples of organisms is of some interest. Perch was able to identify every one of Winkle's eight somatic types (excluding the $\mathbf{X}$ types) with one of her own (Perch, 1948). Some of the organisms in the two collections were isolated from geographically continuous regions, i.e. Denmark and Germany, although some of Winkle's strains came from Poland or the Polish-German frontier region. Our strains were collected in Britain (London and Birmingham). In all these collections the strains were of human origin. Perch's $\mathbf{O}$ group 10 (our $\mathbf{O}$ type 3 ) is particularly interesting. The strains of this group form $14.4 \%$ of the 388 strains represented in Perch's extended scheme, and $\mathbf{1 8 . 2} \%$ of the typable strains in our collection; that is, in both cases, the type is one of the most common, if not the most common, somatic antigen. It is completely absent from Winkle's strains; and since these numbered over 1000 it seems unlikely that its absence from his collection is due merely to errors of random sampling. It is conceivable that the differences in the distribution of $\mathbf{O}$ antigens in these collections is due 
to the limited geographical distribution of the various $O$ antigenic types. Alternatively, the apparent dissimilarity in somatic antigen constitution between our collection of strains and that of Perch, may in our own series be the result of the selection only of strains that were in phase $\mathbf{A}$ or could be induced to revert to it, with the consequent elimination of certain antigens found widely distributed in degenerate strains which are characterized by the more cosmopolitan phase $\mathrm{B}$ and $\mathrm{C}$ antigens.

\section{Applications of Proteus typing}

Much information of epidemiological and clinical interest may emerge from typing Proteus strains. In this connexion it is worth recording the $\mathbf{O}$ types of strains PR 41-58 isolated on two occasions from infected patients in a burns ward (Table 12). The result, though not conclusive, suggests that the hospital infection of wounds and burns, recognized with staphylococci and streptococci, might also be demonstrated unequivocally with typed $\boldsymbol{P}$. vulgaris.

On the first occasion, type 5 was found in six of ten infected patients; and patients nos. I and IV swabbed at an interval of a few days had either a mixed infection or a replacement of type by another (untypable $\rightarrow \mathrm{XK}, 3 \rightarrow 5$ ). On the second occasion, investigated a few weeks later, types 5 and $\mathbf{3}$ are still prevalent.

Table 12. O-antigenic types isolated during two outbreaks of Proteus infection in burns

$\begin{array}{lccc}\text { Patient } & \begin{array}{c}\text { Type of } \\ P . \text { vulgaris }\end{array} & \text { Patient } & \begin{array}{c}\text { Type of } \\ \text {. vulgaris }\end{array} \\ \text { I } & \left\{\begin{array}{c}\text { (not typable }) \\ \text { XK }\end{array}\right. & \text { VIII } & 5 \\ \text { II } & \mathbf{9} & \text { X } & 6 \\ \text { III } & 5 & \text { XI } & 5 \\ \text { IV } & \{3 & \text { XII } & 7 \\ \text { V } & \{5 & \text { XIII } & 5 \\ \text { VI } & 5 & \text { XIV } & 3 \\ \text { VII } & 5 & \text { XV } & 5 \\ \text { II } & 3 & 15\end{array}$

The strains isolated from patients I, IV and XII were in each case obtained within a few days.

\section{DISCUSSION}

Our analysis of the fifty strains is incomplete in two senses: $(a)$ we have not made antisera to all the $\mathbf{H}$ strains, and so do not know the entire cross-reactivity of the collection; and $(b)$ we have based our classification on the orthodox $\mathrm{O}$ and $\mathrm{H}$ antigens. With regard to $(a)$, we felt it sufficient to demonstrate, as others have recently done, the antigenic heterogeneity of the $\boldsymbol{P}$. vulgaris; the fact that $\mathrm{H}$ antigens are shared by strains with quite different $\mathrm{O}$ antigens; the occurrence of OX strains (in our limited collection only type OXK) in situations remote from typhus infections; and a concordance of some of our types with those in other collections. We do not wish necessarily to perpetuate our numbered typing of $\mathrm{O}$ antigens, nor the lettered grouping of $\mathbf{H}$ antigens. The proper 
naming of the types and groups must follow concerted action by workers in the field, whose strains are extant.

With regard to $(b)$, our $\mathrm{O}$ antigens are those which, as bacterial suspensions, withstand heating at $95^{\circ}$, and treatment with ethanol or dilute mineral acid; and which, as bacterial extracts, withstood tryptic digestion followed by ethanol precipitation or exposure to formamide at $150^{\circ}$. Their serology was similar, whichever of the five treatments was used. But it is quite possible that other important surface antigens are destroyed by these processes and do not appear in the analysis. Moreover, the analysis was made only upon strains in what we regard as the modal $\mathbf{S}$ form of recently isolated strains-the phase $\mathbf{A}$ of Belyavin-and it is possible, by extending the analysis to antigens that predominate on the surface of phase $\mathrm{B}$ and phase $\mathrm{C}$ strains, that significant grouping might appear. The existence of phasic changes is suggested both by our own work and by Perch (1948) who described the induction of new flagellar antigens in three strains, two of them with identical somatic antigens. She reported also 'incomplete antigens' which appeared erratically in successive cultures of a given strain, but does not appear to use them in her antigenic scheme. In any event, the serological qualities of the various phases, of which only three are yet known, necessitate a careful serological study of the antigenic configuration of common variants of $\boldsymbol{P}$. vulgaris, including its Rough forms, as a preliminary to a definitive classification.

Some interest attaches to the precise status to be accorded to the somatic XK type. Antigens of this type were found in two strains in our collection (PR 30 and PR 42) which also carried antigens (type 3) of other types. Two such strains (F 58 and F 151) were also detected in the seventy-one strains received from Dr Kauffmann. Winkle (1944), in his somatic antigenic table, lists two other somatic groups which carry one antigen common to the OXK group, in addition to antigens characteristic of their own. Hemmes (1948), in a survey of ninety strains of $\boldsymbol{P}$. vulgaris, tested serologically against eight scrub-typhus sera agglutinating the OXK strain to a high titre, reports the wide distribution of XK antigen, which she identified in a very large proportion of her strains both by agglutination and absorption tests. Only five rabbit anti-proteus sera were used. It is noteworthy that thirty-four of her ninety strains were autoagglutinable.

The sharing of antigens from groups other than OXK is not found in any strain in our series, which however is limited in number. In the $\mathbf{3 8 8}$ strains analysed in the extended schema of Perch, however, only one other strain is listed as sharing a somatic antigen from a group other than OXK.

Winkle gives three somatic groups with one antigen in common, distinct from any found in the OXK group. According to Perch, however, these three somatic groups form three subgroups of her own somatic group 23, and may therefore merely represent the members of a heterogeneous somatic group. The evidence therefore points to the XK group as being the outstanding possessor of this peculiarity. The question therefore arises as to whether some of the OXK antigens concerned are not characteristic of a distinct phase in an antigenic variation. 
With regard to the relation of the 'mirabilis' and 'vulgaris' varieties, it is to be noted that there we found no $O$ antigens shared by strains of the two types; but the number of 'vulgaris' varieties in our collection was too small to give this observation much weight in determining whether the two fermentative types deserve specific rank.

We are indebted to Lt.-Col. H. J. Bensted and Dr L. Colebrook for strains, and particularly to Dr F. Kauffmann and Dr B. Perch of the State Serum Institute, Copenhagen, who generously put the key strains of their collection at our disposal.

\section{REFERENCES}

Belyavin, G. (1951). Cultural and serological phases of Proteus vulgaris. J. gen. Microbiol. 5, 197.

Bengston, I. A. (1919). The Proteus group of organisms with special reference to agglutination and fermentation reactions and to classification. J. infect. Dis. 24, 428.

Bergey's Manual of Determinative Bacteriology. (1948) 6th ed. Breed, R. S., Murray, E. G. D. \& Hitchens, A. P. (editors). London: Baillière, Tindall and Cox.

Сantu, Сн. (1911). Le bacillus proteus, sa distribution dans la nature. Ann. Inst. Pasteur, 25, 852.

Colquhoun, D. B. \& Kirkpatrick, J. (1932). The isolation of motile organisms from apparently non-motile cultures of $B$. typhosus, B. proteus, B. pestis and B. melitensis. J. Path. Bact. 35, 367.

Dreyer, G. \& Inman, A. C. (1917). The agglutination curve and its importance in the diagnosis of typhoid and paratyphoid fevers in inoculated persons. Lancet, i, 365 .

Duncan, J. T. (1935). Inactivation of the ' $H$ ' antigen by dilute mineral acid. Brit. J. exp. Path. 16, 405.

Felix, A. (1923). Ưber Varianten der Proteus X Stämme. Z. ImmunForsch. 35, 57.

Fletcher, W. \& Lesslar, J. E. (1926). The Weil-Felix reaction in sporadic tropical typhus. Bull. Inst. med. Res. F.M.S., no. 1.

Fuluer, A. T. (1938). The formamide method for the extraction of polysaccharides from haemolytic streptococci. Brit. J. exp. Path. 19, 130.

Gladstone, G. P. \& Fildes, P. (1940). A simple culture medium for general use without meat extract or peptone. Brit. J. exp. Path. 21, 161.

Hemmes, L. (1948). Bijdrage tot der kennis van het geslacht Proteus. Wageninjen: Vienman and Zoren.

Honowitz, A. (1916). Contribution à l'étude du genre Proteus vulgaris. Ann. Inst. Pasteur, 30, 307.

Kauffmann, F. \& Perch, B. (1947). On the occurrence of Proteus $X$ strains in Denmark. Acta path. microbiol. scand. 24, 135.

Kineneberger, C. (1908). Klinische und kritische Beiträge zur Differenzierung pathogenen Proteus Arten und Beiträge zur Wertung der Proteus Agglutination. Z. Hyg. InfehtKr. 58, 85.

Loghem, J. J. van \& Loghem Pouw, J. G. W. van (1912). Beitrag zur Differenzierung der Proteus Gruppe. (B. proteus anindologenes). Zbl. Bakt. (1 Abt.) 66, 19.

Miles, A. A. (1951). The mouse-virulence and toxicity of Proteus vulgaris. J. gen. Microbiol. 5. (In the Press.)

Moltke, O. (1927). Contributions to the characterization and systematic classification of B. proteus vulgaris (Hauser). Copenhagen: Levin and Munksgaard.

Pampana, E. J. (1933). Microbic dissociation: detection of the ' $R$ ' variant by means of a specific drop agglutination. J. Hyg., Camb., 33, 402. 
Pandit, S. R. \& Wirson, G. S. (1932). The relation between specific and non-specific agglutination in the Brucella group. J. Hyg., Camb., 32, 45.

Perch, B. (1948). On the serology of the Proteus group. Acta path. microbiol. scand. $25,703$.

Rustigian, R. \& Stuart, C. A. (1945). Biochemical and serological relationships of organisms of genus Proteus. J. Bact. 49, 419.

Stamp, Lond (1947). The preservation of bacteria by drying. J. gen. Microbiol. 1, 251.

Taylon, J. F. (1928). B. proteus infections. J. Path. Bact. 31, 897.

VARELA, G., Zozaya, J. \& Imaz, F. (1944). Structural and serological analysis of intestinal group of proteus. Rev. d. Inst. salub. y enferm. trop. $5,15$.

WeIL, E. (1920). Über Varianten des Stammes X19. Wien. klin. Wschr. 33, 61.

WEIL, E. (1923). Variationsuntersuchungen bei X19. Z. ImmunForsch., 35, 25.

Weil, E. \& Felix, A. (1916). Zur serologischen Diagnose des Fleckfieber. Wien. klin. Wschr. 29, 33.

Weil, E. \& Felix A. (1917). Weitere Untersuchungen über das wesen Fleckfieberagglutination. Wien. klin. Wschr. 30, 1509.

Wenner, J. J. \& Retrger, L. F. (1919). A systematic study of the Proteus group of bacteria. J. Bact. 4, 331.

WrnkLe, S. (1943). Untersuchungen zur Weil-Felix reaktion. Zbl. Bakt. (1 Abt.), $151,3$.

Winkue, S. (1944). Zur Typendifferenzierung in der Gattung Proteus Hauser. Zbl. Bakt. (1 Abt.), 151, 494.

Wolf, S. (1899). Beiträge zur Lehre der Agglutination mit besonderer Bezugnahme auf die Differenzierung der Coli- und Proteus-gruppe und auf die Mischinfektion. Zbl. Bakt. (1 Abt.), 25, 311.

YАСОВ, M. (1932). Studies of genus Proteus. Indian J. med. Res. 19, 787.

(Received 20 April 1950) 